\title{
Germanica
}

les pays germanophones de 1880 à nos jours

\section{La pensée allemande et les débuts de la tradition philosophique roumaine}

Die deutsche Kultur und die Anfänge der rumänischen Philosophie

German thought and the dawn of the Romanian philosophical tradition

Cécile Folschweiller

\section{OpenEdition}

Journals

Édition électronique

URL : http://journals.openedition.org/germanica/4837

DOI : $10.4000 /$ germanica. 4837

ISSN : 2107-0784

Éditeur

Université de Lille

Édition imprimée

Date de publication : 31 juillet 2018

Pagination : 143-157

ISBN : 9782913857414

ISSN : 0984-2632

Référence électronique

Cécile Folschweiller, "La pensée allemande et les débuts de la tradition philosophique roumaine », Germanica [En ligne], 62 | 2018, mis en ligne le 31 juillet 2020, consulté le 15 janvier 2021. URL : http:// journals.openedition.org/germanica/4837 ; DOI : https://doi.org/10.4000/germanica.4837 


\title{
La pensée allemande et les débuts de la tradition philosophique roumaine
}

\author{
Cécile FOLSCHWEILLER \\ INALCO Paris
}

Parler d'école philosophique roumaine n'est pas possible avant la fin $\mathrm{du} \mathrm{XIX}^{\mathrm{e}}$ siècle. Les deux premières universités roumaines furent créées en 1860 à Iaşi puis en 1864 à Bucarest, dans le contexte de la toute récente union des deux principautés de Moldavie et de Valachie, en 1859, sous le sceptre du prince Alexandru Ioan Cuza. Mais la pensée philosophique émerge dans la culture roumaine, et en roumain, dès le début du XIX siècle, favorisée à la fois par les contacts intellectuels avec le reste de l'Europe et par les questionnements collectifs liés au problème national ${ }^{1}$. Ces deux facteurs sont loin d'être sans lien : la grande question des voies ou modèles de développement de la nation roumaine, qui naît alors et court jusqu'au $\mathrm{XX}^{\mathrm{e}}$ siècle, devient obsessionnelle dans la seconde moitié du XIXe siècle et se décline de multiples manières, mais revient toujours à se demander s'il faut adopter un modèle extérieur (occidental ou oriental, français ou allemand) ou cultiver des traditions autochtones. Question existentielle qui s'insère dans les réflexions des premiers intellectuels roumains et les infléchit, expliquant sans doute

1. - Cette problématique de la philosophie roumaine liée à la question nationale est l'un des fils conducteurs de notre étude, centrée sur la seconde moitié du XIXe siècle, où sont développés plusieurs aspects de cet article : Cécile Folschweiller, Philosophie et nation. Les Roumains entre question nationale et pensée occidentale au XIXe siècle, Paris, Champion, 2017. 
pourquoi le paysage philosophique roumain nous est à la fois proche, par sa terminologie et ses références aux auteurs occidentaux, et étranger, par les problématiques qui établissent son centre de gravité autour des concepts d'identité et d'existence nationale, dont le statut philosophique est problématique dans la tradition française par exemple. Ce fait nous rappelle que la philosophie, loin d'être détachée de l'expérience historique et du contexte culturel, est toujours située. Costica Bradatan a bien montré comment, en l'occurrence, le mode d'être historique des Roumains, placé sous le signe de la « précarité » et de la « fragilité » 2 , a contribué à produire une tradition philosophique qui a privilégié certains problèmes

[...] dont la solution était extrêmement urgente pour le métabolisme de la vie intellectuelle et spirituelle locale, et qui tous émergeaient au fil d'un effort sincère de compréhension de soi : l'identité collective/nationale (et ses caractères incertains), les ressorts intimes de l'identité de soi, la fatalité (et le «boycott ») de l'histoire, la marginalité et l'éternelle « recherche du centre », la création culturelle et l'originalité comme jalons ontologiques, la langue comme Haus des Seins, etc. ${ }^{3}$.

L'apparition ici d'un concept allemand, heideggérien, est révélatrice. S'il est un espace culturel qui a marqué la réflexion philosophique dans cette Roumanie pourtant pétrie de culture latine, c'est bien l'espace germanique. En témoignent par exemple la place prise dans les deux pays, dans le paysage disciplinaire de la philosophie, par la «philosophie de la culture » (Kulturphilosophie), catégorie absente de la tradition philosophique française, et l'horizon de formation, de lecture et de réflexion, fortement ancré dans l'espace germanique, des grands philosophes roumains, de Titu Maiorescu (1840-1917) à Constantin Noica (1909-1987), en passant par Constantin Rădulescu-Motru (1868-1957) ou Lucian Blaga (1895-1961), entre autres. Cette conjonction philosophique roumano-allemande s'explique en partie par des similitudes de situation historique, souvent soulignées ${ }^{4}$ : les Roumains comme les Allemands ont eu à penser leur existence collective et nationale pour la faire advenir dans l'adversité.

2. - Voir son introduction (intitulée «Philosophy, Geography, Fragility ») au volume qu'il a coordonné : Costica Bradatan, Philosophy, Society and the Cunning of History in Eastern Europe, Londres, New York, Routledge, 2012, p. 3.

3. - Costica Brădăţan, Introducere la istoria filosofiei româneşti în secolul XX [Introduction à l'histoire de la philosophie roumaine au XXe siècle], Bucarest, Editura Fundaţiei culturale române, 2000, p. 12. Les traductions du roumain nous appartiennent.

4. - Citons entre autres Ştefan Zeletin, « Romantismul german şi cultura critică română » [ « Le romantisme allemand et la culture critique roumaine »], Minerva, II, 3, Iaşi, 1929, p. 63-83. 
Dans l'impossibilité de suivre l'ensemble de ces confluences philosophiques, nous nous proposons ici de nous concentrer essentiellement sur le grand XIX⿸ siècle pour dégager, dans l'espace intellectuel roumain, les points de rencontre saillants avec la pensée allemande, qui sont importants pour saisir les débats philosophiques roumains du $\mathrm{XX}^{\mathrm{e}}$ siècle. Les pistes étant nombreuses et variées dans le champ des transferts culturels - formation et parcours des auteurs, circulation et réception des textes, usage des concepts, évolution des problématiques, institutions et structures académiques, etc. -, nous procéderons par périodes. La nécessité de remonter à la première moitié du XIXe siècle pour envisager les rapports germano-roumains en matière d'histoire des idées, quitte à déborder en amont les limites chronologiques proposées pour ce dossier, répond à la volonté de rééquilibrer une vision schématique des choses qui s'est longtemps imposée dans l'historiographie roumaine et qui voyait dans la génération quarante-huitarde (1830-1860) l'expression accomplie de l'influence française (libérale, voire révolutionnaire), suivie d'un grand virage vers le modèle allemand conservateur alimenté par la philosophie de l'idéalisme métaphysique, impulsé par le cénacle littéraire et intellectuel Junimea, correspondant historiquement au règne du prince puis du roi Carol de Hohenzollern (1866-1914). La situation est en réalité plus complexe et fait de la Roumanie un cas d'école particulièrement riche en matière de transferts culturels.

\section{Les débuts et la génération quarante-huitarde : premiers contacts avec la pensée allemande}

La première moitié du $\mathrm{XIX}^{\mathrm{e}}$ siècle est déjà représentative du tropisme francophile chez les Roumains cultivés, comme en témoignent les traductions réalisées en roumain. Une étude statistique déjà ancienne, mais qui continue de faire référence, établie sur la période 1780-1860, montre que sur 679 titres traduits en roumain - œuvres littéraires, philosophiques et scientifiques - 385 l'étaient du français pour seulement 83 de l'allemand ${ }^{5}$. L'espace roumain n'est alors unifié ni politiquement, ni culturellement. Tandis que dans les deux principautés de Moldavie et de Valachie, sous suzeraineté ottomane, le règne des princes phanariotes (1715-1821), avec leurs bibliothèques, précepteurs et écoles, a favorisé, par l'intermédiaire de la langue grecque, une ouverture à la culture française, dans la Transylvanie habsbourgeoise et pluriculturelle, les Roumains, population très majoritairement rurale et paysanne, ont peu de possibilités de développer leur culture dans le cadre d'institutions. C'est cependant par là que la culture germanique, assez naturellement,

5. - Paul Cornea, De la Alecsandrescu la Eminescu [D'Alecsandrescu à Eminescu], Bucureşti, E.P.L., 1966, p. 48. 
a fait son entrée dans l'univers intellectuel roumain, au sein de l'École transylvaine. Ce mouvement, que les Roumains qualifient souvent de "Lumières roumaines », s'épanouit entre les années 1780 et 1820 et se distingue par une action d'émancipation culturelle (fondation de nombreuses écoles en langue roumaine et en particulier l'école supérieure de Blaj) et une œuvre intellectuelle pionnière en matière de philologie (premières grammaires roumaines, dictionnaires plurilingues) et d'histoire, valorisant la latinité des Roumains. Mais si l'idéologie émancipatrice est forte, elle ne s'accompagne pas d'une mise en question de la théologie et de la religion, les meneurs du mouvement étant issus de l'église uniate (gréco-catholique), statut qui leur a permis de se former dans les collèges de Vienne et de Rome. On ne peut parler ici d'influence des Lumières allemandes mais plutôt d'une certaine conjonction temporelle et d'un esprit général en accord avec l'Aufklärung' ${ }^{6}$. Cependant, il faut souligner le rôle catalyseur et unificateur que donne à ces préoccupations la prise en compte de la philosophie comme discipline émancipatrice ${ }^{7}$. Elle se manifeste par un travail de traduction qui permet d'introduire dans la culture roumaine la filiation LeibnizWolff-Baumgarten par l'intermédiaire du traité de Friedrich Christian Baumeister (Elementa philosophiae... de 1781) dont Samuil Micu traduit et publie en 1799 et 1800 deux parties en roumain, la Logique et l'Éthique, les autres restant sous forme de manuscrit.

Dans les Principautés, c'est à partir des années 1830, après le traité d'Andrinople qui marque un recul de l'emprise ottomane, que la culture roumaine lettrée s'épanouit avec la fondation de journaux, de théâtres, d'académies, et une circulation des idées et des textes qui s'intensifie fortement. La génération qui à la fois profite de cette évolution et la met en œuvre durant la période 1830-1860 par son activité intellectuelle, culturelle et militante, est aussi celle qui mène les mouvements d'émancipation nationale de 1848, en Moldavie et Valachie comme en Transylvanie. L'orientation vers la pensée française reste prépondérante, en particulier chez les Valaques, mais les quarante-huitards transylvains formés à l'École de Blaj, ainsi que certains Moldaves (Mihail Kogălniceanu par exemple) combinent les sources franco-allemandes.

Plusieurs facteurs ont contribué à une ouverture de cette génération à la culture et à la pensée allemandes. Certains sont communs avec ceux qui encouragent le mouvement francophile, à commencer par la prise de conscience du retard à rattraper, qui pousse les Roumains à

6. - Dan Mănucă, « Die Verbreitung des deutschen Modells in der rumänischen Kultur (1848-1918) », in : Alexander Rübel (dir.), Rumänien in Europa, Konstanz, Hartung-Gorre Verlag ; Iaşi, Editura Universităţii A. I. Cuza, 2002, p. 106.

7. - Ion Ianoşi, O istorie a filosofiei româneşti [Une histoire de la philosophie roumaine], Cluj, Biblioteca Apostrof, 1996, p. 35-40. 
se tourner vers les classiques occidentaux considérés comme fondamentaux pour le développement d'une culture nationale. C'est ainsi qu'Heliade-Rădulescu, pourtant prioritairement tourné vers les espaces français et italiens, fait figurer dans son projet de Bibliothèque universelle, parmi les titres à traduire, Herder (Ideen zu einer Philosophie der Geschichte der Menschheit), Lessing (Laokoon et Die Erziehung des Menschengeschlechts), Leibniz, Kant (les deux Critiques), Wolf, Fichte, Hegel, Schelling, Schiller, Goethe, entre autres ${ }^{8}$. Ce vaste programme restera en très grande partie à l'état de projet mais témoigne de l'attention portée à l'espace germanophone au nom d'un héritage européen déjà considéré comme classique et qu'il est urgent de s'approprier.

Une autre raison de valoriser le patrimoine intellectuel allemand est au contraire la volonté de contrebalancer le poids de la culture française, que certains, tel le quarante-huitard Ioan Maiorescu, considèrent comme envahissante et dangereuse pour la culture roumaine. Ainsi, le jeune Mihail Kogălniceanu, parti en 1834 faire ses études en France avec les fils du prince Sturdza de Moldavie, ne découvrira pas Paris à cette occasion : à la capitale française, considérée comme trop libérale et révolutionnaire, le prince a préféré une tranquille petite bourgade de Lorraine, Lunéville, pour l'éducation de ces jeunes Moldaves. Et lorsqu'il s'agit d'Université, un an plus tard, c'est à Berlin qu'on les envoie : «En Allemagne, constate le jeune Kogălniceanu, on est plus tranquille, l'instruction est plus profonde, les mœurs sont plus innocentes et les coutumes plus patriarcales ${ }^{9}$. Il y rencontre Alexander von Humboldt, y écoute les cours d'Eduard Gans (droit naturel), de Karl von Savigny (droit historique) et de Leopold von Ranke (histoire moderne), les deux derniers étant particulièrement importants pour l'orientation d'historien de Kogălniceanu et l'accent mis sur un développement lent, progressif et respectueux des traditions qu'il préconise pour la culture roumaine.

Certes, ces noms ne constituent pas les références principales des quarante-huitards roumains et Paul Cornea, refusant les longues listes peu vérifiables d'auteurs prétendument «influents », limite celle-ci à quatre noms allemands ayant vraiment pesé dans la pensée de cette génération roumaine : Herder, Schiller, Kant et Rotteck ${ }^{10}$. Karl von Savigny nous semble devoir être sinon ajouté, du moins évoqué : le chef de l'école du droit historique est en effet cité explicitement dans l'im-

8. - Paul Cornea, «Die deutsche Kultur und die achtundvierziger Bewegung in Rumänien », in : Klaus Heitmann (dir.), Rumänisch-deutsche Interferenzen, Heidelberg, Carl Winter, 1986, p. 77.

9. - Mihail Kogălniceanu, Scrieri [Écrits], Bucureşti, 1913, p. 141 ; Paul Cornea, «Die deutsche Kultur... », op. cit., p. 83.

10. - Paul Cornea, « Die deutsche Kultur... », op. cit., p. 84-85. 
portant discours de Blaj prononcé en 1848 par Simion Bărnuţiu pour montrer, contre les projets hongrois d'intégration de la Transylvanie, que l'unification du droit, comme celle de la langue, loin de garantir l'unité d'un État, nuit au sentiment d'appartenance des individus, qui ont besoin de rester enracinés dans leurs traditions. Bărnuţiu devient ensuite le premier professeur de droit à l'Université de Iaşi où il développe sa thèse du retour au droit romain, au nom de l'origine latine des Roumains. La combinaison, voire la confusion que font les penseurs roumains, des thèses du droit naturel et du droit historique selon leurs besoins intellectuels et nationaux est typique de leur argumentation, et la transposition dans l'espace roumain des débats allemands sur le droit se poursuivra dans les années 1870-1880 avec Alexandru Xenopol. Contrairement au schéma interprétatif valorisé par l'historiographie roumaine de l'époque communiste, un certain nombre de quarante-huitards roumains, notamment moldaves et transylvains, sont donc déjà marqués par la pensée allemande conservatrice, évolutionniste et organiciste qui va s'épanouir plus librement dans la génération suivante.

Il faut s'arrêter enfin un instant sur le nom de Herder dont l'importance pour les penseurs de toute l'Europe centrale et orientale a été soulignée à raison. Ses travaux sur le folklore, eux-mêmes largement consacrés aux cultures slaves et nordiques, ont facilité la réception dans la région de ses thèses sur l'importance des "caractères nationaux » qui n'ont pas peu contribué à la maturation de la prise de conscience nationale dans ces pays. L'auteur est passé d'Allemagne dans la culture roumaine par deux itinéraires différents. Le premier est direct mais son écho immédiat reste faible : c'est celui qui amène ses œuvres dans les bibliothèques des esprits éclairés de Transylvanie. George Bariţiu en recommande la lecture, Ioan Maiorescu et Florian Aron la pratiquent assidûment. Le second est indirect mais ses intermédiaires lui donnent de la portée : c'est celui de la traduction française des Idées sur la philosophie de l'histoire de l'humanité par Edgar Quinet en 1827 et de l'interprétation proposée par son collègue historien Jules Michelet au Collège de France que fréquentent les jeunes Roumains. Cette réception indirecte contribue à enrichir les concepts de «nation » et de «peuple » chez les Roumains qui combinent les déterminations françaises (politiques) et allemandes (ethniques et culturelles) de ces notions dans un discours particulièrement souple et apte à s'adapter à différents besoins argumentatifs.

On voit avec le cas de Herder comment la pensée philosophique rejoint les préoccupations nationales du moment dans l'Europe du milieu du XIXe siècle. Pourtant, chez les Roumains, la conjonction que nous avons mentionnée en introduction entre l'affirmation identitaire et le développement de la réflexion philosophique n'est pas évidente au début, il s'agit encore dans ces années-là de deux préoccupations 
relativement distinctes et de deux activités menées d'un côté par des militants de la cause nationale engagés politiquement, et qui, intellectuellement, sont plutôt ancrés dans l'histoire et la philologie, de l'autre par des professeurs s'attachant à importer et traduire un enseignement académique qui fait défaut en langue roumaine. Et leurs références, du point de vue philosophique, ne sont pas forcément très compatibles. Le manuel allemand qui sert de base à l'enseignement est celui de W. T. Krug, le successeur de Kant à Königsberg. Traduit en roumain une première fois par A. T. Laurian en 1847, puis par T. Cipariu en 1861, il n'est pas favorable à Herder, l'antikantien notoire, dont les mérites comme philosophe sont discutables, selon l'auteur du manuel ${ }^{11}$. La polémique qui a opposé Kant à Herder à propos de la philosophie de l'histoire recoupe d'une certaine manière la tension implicite entre l'orientation vers l'Aufklärung rationaliste et universaliste des premiers enseignants roumains (citons Eufrosin Poteca, puis Ioan Zalomit, tous deux kantiens) et celle des quarante-huitards engagés pour la cause nationale. La combinaison du droit naturel et du droit historique que propose Simion Bărnuţiu, le plus compétent d'entre eux en matière de philosophie, achoppe sur la contradiction entre l'universel et le particulier qui sous-tend l'œuvre de Herder.

\section{Titu Maiorescu et le cénacle Junimea : un usage sélectif de la philosophie allemande}

Cette contradiction, il revient à l'un des adversaires de Bărnuţiu, de la génération suivante, de la pointer : Titu Maiorescu, meneur du cénacle Junimea mais aussi philosophe de formation puis professeur de philosophie, entre autres activités politiques et littéraires, est l'auteur d'une critique décapante de la culture roumaine, qui commence par s'en prendre aux réalisations de l'École transylvaine et des quarante-huitards au nom de l'universalisme rationaliste. Il leur est reproché d'avoir sacrifié la vérité et la beauté à la cause roumaine. Une œuvre n'est pas belle ou bonne parce qu'elle est roumaine, écrit Maiorescu, rappelant la «distinction des sphères » du Beau, du Vrai et du Bien, ou encore de l'esthétique, de la science et de la politique, en s'appuyant sur des définitions proches de celles de l'idéalisme allemand. La critique se généralise et se fixe avec la formule des «formes sans fond » qui vise toutes les réalisations hâtives et récentes de la culture roumaine reposant sur le faux, sur des bases viciées, sur une distorsion de la vérité et sur un décalage avec la réalité : pseudo-science, littérature médiocre, institu-

11. - Johann Wolf, « La pensée de Herder dans l'idéologie de la génération roumaine de 1848 en Transylvanie », in : Romul Munteanu (dir.), Le Comparatisme roumain, vol. II, Bucarest, Univers, 1985, p. 180-198. 
tions culturelles de façade et incompétentes, discours patriotiques vides, constitution politique copiée de modèles occidentaux et inadaptée à la société roumaine, le tout motivé par le désir d'affirmation de l'identité roumaine à tout prix. Que cette critique soit le fait d'un jeune homme formé à la philosophie (entre autres disciplines) à Vienne, Berlin et Paris n'est pas un hasard. Outre le regard comparatif apte à mesurer les décalages culturels, l'esprit affûté aux critères de jugement et sensible aux grandes systématisations historiques, scientifiques et intellectuelles se voit ici.

L'accusation de germanophilie adressée aux Junimistes et particulièrement à leur chef remonte à la naissance même du cénacle, aux années 1860. Elle émane d'une élite intellectuelle bucarestoise très francophile et d'une idéologie nationale arc-boutée sur l'argument de la latinité. Sans doute y a-t-il une volonté de corriger cette image chez Maiorescu caractérisant, des années plus tard, l'esprit de Junimea comme «plus anglais évolutionniste que français révolutionnaire ${ }^{12} »$. La formule est souvent citée pour illustrer sa critique de l'idéologie des meneurs valaques du mouvement quarante-huitard devenus ses adversaires politiques, mais sa référence anglaise positive, qui renvoie à l'évolutionnisme mais aussi au libéralisme et au positivisme, a été longtemps laissée de côté, car elle entrait difficilement dans le vieux schéma interprétatif hérité de l'époque communiste qui voit dans l'idéalisme et le conservatisme allemands la source première des Junimistes. L'absence de l'Allemagne dans le propos de Maiorescu déroute, mais elle correspond aussi à une prise de position philosophique. Il s'agit de marquer ses distances avec une certaine philosophie allemande, l'idéalisme métaphysique de Fichte, Schelling et Hegel auquel on la réduit trop souvent. Les œuvres citées par Maiorescu pour illustrer les préoccupations de Junimea au début des années 1870 sont l'Histoire de la civilisation de Thomas Buckle, L'asservissement des femmes de John Stuart Mill, qui venait de paraître, et celle d'un auteur allemand, Arthur Schopenhauer, évoqué pour ses réflexions sur l'histoire. Pour Maiorescu, qui vitupérait dans sa jeunesse contre l'esprit de clocher national en matière de philosophie, ce n'est pas tant l'opposition entre esprits nationaux qui compte que l'opposition entre esprits philosophiques. Il s'agit ici de montrer qu'en matière de jugement sur les faits, l'histoire et les sociétés, la démarche inductive, empiriste, est supérieure à la spéculation a priori. Et de ce point de vue, l'idéalisme allemand ne vaut pas mieux que la pensée française révolutionnaire. La simple traduction et publication par Maiorescu dans la revue de Junimea de l'article de Schopenhauer « Contre la philoso-

12. - Titu Maiorescu, Istoria politică a României sub domnia lui Carol I [Histoire politique de la Roumanie sous le règne de Carol I] [1897-1915], Bucarest, Humanitas, 1994, p. 33. 
phie universitaire », véritable pamphlet contre le trio Fichte-SchellingHegel, suffit à le montrer. Car quel sens pouvait avoir un tel texte dans la Roumanie de 1870 encore dépourvue de toute tradition philosophique universitaire ? Schopenhauer, en dénonçant le vide de la philosophie idéaliste allemande, devait ouvrir les yeux au public roumain sur l'analogie de tous les discours prétentieux et formels, qu'ils soient philosophiques, politiques ou culturels. Ses textes sur l'histoire sont un autre pied de nez aux grandes constructions de Hegel, que Maiorescu a rapidement abandonnées, comme il a abandonné la métaphysique. Les préoccupations concrètes et urgentes des Roumains, d'ordre culturel, politique et historique, le mènent vers une sélection sévère des thèses, concepts et analyses philosophiques pertinentes. Ce qui l'intéresse chez Schopenhauer, lorsque l'on recoupe ses références, c'est sa critique de la civilisation de façade, des « représentations » du monde qui ne sont que formelles et superposées aux jeux de la «volonté » qui anime intérieurement ce monde, bref, une sensibilité philosophique qui sait distinguer les «formes » et le « fond », ou encore ce que Clément Rosset a appelé «l'intuition généalogique » chez ce spécialiste de «l'analyse critique de la surface ${ }^{13} »$. Le jeune Maiorescu avait déjà retenu cet aspect dans la pensée de Ludwig Feuerbach, lu avec enthousiasme durant ses études.

Mais l'héritage sans conteste le plus fécond de la philosophie allemande est pour lui celui de Kant, celui de la philosophie critique ramenant les formes de la représentation à ses conditions de possibilité - pour reprendre le vocabulaire philosophique kantien. Les références enthousiastes au philosophe de Königsberg, pour lequel seul il avoue "un respect illimité14 », ponctuent ses travaux philosophiques de jeunesse, son journal et sa correspondance, il traduit des fragments de la Critique de la raison pure et lui consacre une large place dans le cours de philosophie qu'il tient à Bucarest jusqu'en 1906. La critique kantienne des « autorités » en matière de théologie et de législation, la distinction entre les domaines du Vrai, du Bien et du Beau, l'analyse des facultés de l'esprit, tout cela constitue chez Maiorescu un arrière-plan philosophique permettant de comprendre la cohérence de ses préoccupations centrées sur les conditions de possibilité de la culture et de l'éducation. Et bien au-delà d'un simple parallélisme formel, la célèbre formule de Kant selon laquelle « des pensées sans matière sont vides ; des intuitions sans concept sont aveugles » nous apparaît comme l'une des sources philosophiques de la critique des « formes sans fond».

Bien d'autres références à la pensée allemande alimentent les réflexions de Maiorescu et des Junimistes, issues de ce qu'on a pu

13. - Clément Rosset, Écrits sur Schopenhauer, Paris, PUF, 2001, p. 88.

14. - Titu Maiorescu, Jurnal şi epistolar III, Bucureşti, Minerva, 1980, p. 449, 201. 
appeler « l'autre XIX ${ }^{\mathrm{e}}$ siècle allemand ${ }^{15}$ », c'est-à-dire tout ce qui reste lorsqu'on a retranché le trio Fichte-Schelling-Hegel : la psychologie de Herbart et la pensée autrichienne logique et empiriste, qui ont enthousiasmé Maiorescu dans sa jeunesse viennoise, la Völkerpsychologie de Lazarus et Steinthal, qui trouve plus d'écho chez Mihai Eminescu et Alexandru Xenopol, le matérialisme de Büchner exploité par Vasile Conta dans sa philosophie de «l'ondulation universelle », les interprétations philosophiques du Kosmos de Humboldt ou celles tirées des avancées scientifiques en matière de biologie, de physiologie, de linguistique, de psychologie. Dans ces domaines où la science peut nourrir la philosophie, l'Allemagne prend nettement le pas sur la France qui reste figée dans la vieille philosophie enseignée à la Sorbonne par les héritiers de Victor Cousin et qui a tant déçu Maiorescu. Ajoutons à cela les travaux d'économie politique de Lorenz von Stein, Dühring ou List, entre autres, particulièrement exploités par Eminescu dans ses articles de presse.

Ces orientations se manifestent dans le choix des textes philosophiques traduits par les Junimistes. Kant fait l'objet de traductions qui, même si elles ne sont pas publiées, n'en sont pas moins importantes pour l'appropriation de sa pensée par l'élite intellectuelle. Maiorescu comme Eminescu se concentrent sur la Critique de la raison pure. Le second notamment traduit, à la fin de ses études, à Berlin, tout le début de l'œuvre : l'Introduction, l'Esthétique transcendantale et une partie importante de l'Analytique transcendantale ${ }^{16}$. Le choix de la première édition de la Critique de la raison pure est à souligner : Eminescu s'inscrit là dans le droit fil de la lecture schopenhauerienne de Kant, qui réévaluait cette première version où l'idéalisme subjectif est plus fort que dans la seconde. Le filtre schopenhauerien a fortement marqué et déterminé la lecture de Kant en Roumanie et on en voit une manifestation littéraire dans la nouvelle Sărmanul Dionis [Le pauvre Dionis], où le poète exploite la thèse de l'idéalité de l'espace-temps pour y faire voyager son héros. À côté de quelques textes moins connus, mais importants, comme l'article du physiologiste Emil Du Bois-Reymond Über die Grenzen des Naturerkennens traduit dès sa parution en 1891, Maiorescu se consacre essentiellement à l'œuvre de Schopenhauer dont il traduit en roumain, outre le texte déjà mentionné, une partie du livre III du Monde comme volonté et comme représentation (consacré à l'art

15. - Nous reprenons l'expression à un numéro de la Revue de Métaphysique et de morale de $2002\left(\mathrm{n}^{\circ} 3\right)$ ainsi intitulé et présenté par J. Benoist. Les articles y sont consacrés à Bolzano, Herbart, Fries, Lange, Helmholtz et aux interprétations empiristes de la Critique de la raison pure. On y trouve de nombreux noms qui ont marqué la pensée des Roumains à la fin du XIXe siècle.

16. - Mihai Eminescu, Lecturi kantiene [Lectures kantiennes], éd. C. Noica, Al. Surdu, Bucarest, Editura Univers, 1975. 
et aux idées esthétiques), trois chapitres des Suppléments du Monde : « de l'esthétique de la poésie » (chap. 37), « de l'histoire » (chap. 38) et « du génie » (chap. 31), et surtout les Aphorismes sur la sagesse dans la vie qui connaîtra cinq éditions du vivant de Maiorescu. Maiorescu a également contribué indirectement à la traduction de Schopenhauer en français : c'est en effet à un Roumain, I. A. Cantacuzino (Cantacuzène, sous la forme francisée), que les Français doivent la première traduction des Aphorismes sur la sagesse dans la vie en 1880 chez GermerBaillière - c'est toujours sa traduction, revue, qui a cours aujourd'hui pour ce texte -, puis De la quadruple racine du principe de raison suffisante en 1882 chez le même éditeur, Le Monde comme volonté et comme représentation, en 1885-86 à Bucarest, Leipzig et Paris et la Critique de la philosophie kantienne en 1889 chez Perrin. Cantacuzène, qui avait été éduqué en Suisse, faisait partie du cercle junimiste de Bucarest, dont plusieurs séances ont été consacrées à revoir et discuter ce travail. Exemple singulier de transfert culturel triangulaire où une culture mineure à l'époque se trouve faire l'intermédiaire entre l'Allemagne et la France, et belle manifestation de l'ouverture d'esprit de cette jeune culture, sur laquelle ne pèse pas de tradition classique, à l'égard d'une pensée encore souvent considérée comme subversive.

Si le leadership de Maiorescu est incontesté à la tête du groupe, de fortes divergences politiques et intellectuelles ne manquent pas d'exister, y compris dans les options philosophiques. Vasile Conta le matérialiste, qui avait fait ses études en Belgique et n'avait pas de culture germanique particulière, avait peu d'affinités avec Maiorescu ; il était proche en revanche d'Eminescu par son goût pour la métaphysique et son nationalisme radical. Celui-ci, germaniste accompli ayant étudié à Vienne puis à Berlin, met aussi Schopenhauer au sommet du panthéon philosophique. Mais sa lecture, complétée par celle de nombreux autres auteurs allemands (E. Dühring, F. List, K. Frantz) mais aussi français et anglais, ce qui est plus rarement souligné, met en valeur d'autres points que celle de Maiorescu : le contrat social économique et la philosophie de l'État naturel et organiciste. Ce faisant, il oriente, plus que Maiorescu, la réflexion vers la recherche du « fond », du contenu qui doit se substituer aux « formes » de la culture d'emprunt, mais aussi du fond des choses, au sens métaphysique de l'expression. Cette tendance métaphysique, qui diverge de la réflexion critique menée par Maiorescu, se retrouve chez Alexandru Xenopol, plus connu comme historien, mais qui écrit, en français, une volumineuse Théorie de l'histoire (1908), qui est en réalité une philosophie de l'histoire. Dialoguant avec les penseurs contemporains français et allemands (H. Rickert, W. Windelband, K. Lamprecht), Xenopol prend sur l'histoire une voie résolument anti-schopenhauerienne et une position spiritualiste forte, cohérente avec son enthousiasme de jeunesse pour la Völkerpsychologie de Lazarus et Steinthal. 
C'est chez lui que l'on retrouve la notion de Volksgeist transposée en roumain avec un flou terminologique qui entretient une interprétation métaphysique forte de la notion. Le «Geist» est en effet souvent traduit par « suflet », c'est-à-dire « âme » en roumain, alors que les deux auteurs allemands avaient pris soin de distinguer fermement les deux notions, rejetant celle de «Seele », et que la langue roumaine dispose aussi du terme « spirit» (esprit). Ultérieurement, le choix parfois fait de traduire «Volk» par «neam » plutôt que «popor » renforcera plus encore les connotations ethniques fortes de l'expression, compte tenu des nuances entre ces deux termes.

\section{Le début du $\mathrm{XX}^{e}$ siècle : les tentations de la métaphysique allemande}

$\mathrm{Au}$ tournant du $\mathrm{XX}^{\mathrm{e}}$ siècle, l'école roumaine de philosophie s'est constituée dans les deux universités de Iaşi et de Bucarest, qui délivrent des licences et leurs premiers doctorats, sous la houlette de professeurs comme I. Zalomit, puis T. Maiorescu ou C. Dimitrescu-Iaşi (lui aussi avec un parcours étudiant en Allemagne, à Leipzig et Berlin), qui forment les premières véritables générations d'enseignants et d'auteurs dans cette discipline. La mise en place de cursus universitaires roumains ne dispense pas encore du détour par l'Europe occidentale et l'on voit Maiorescu envoyer tous ses bons étudiants compléter leur formation en France et en Allemagne : le parcours Paris-Leipzig-Berlin est dans ses grandes lignes comparable pour Ion Petrovici, P. P. Negulescu, C. Rădulescu-Motru. Mais l'orientation germanique du chef et des philosophes de Junimea a marqué les esprits et le tropisme allemand apparaît durablement privilégié dans cette discipline.

Le cas de Constantin Rădulescu-Motru est exemplaire. Formé à Bucarest puis, après deux étapes à Paris et Munich, à Leipzig auprès de W. Wundt, il appartient à la deuxième génération des « maioresciens » et produit un système philosophique original, le « personnalisme énergétique », qui se veut à la fois métaphysique et à vocation pratique, conforme à l'universalité de la rationalité scientifique et adapté à la culture roumaine dont il doit penser la régénération. Aussi bien le concept de « culture », pivot du programme philosophique et défini par opposition à la notion de « civilisation », que les prémisses kantiennes du système sont empruntés à l'héritage philosophique allemand. La critique maiorescienne des « formes sans fond » s'y reformule en termes de « civilisation sans culture », mais le disciple se donne pour tâche de dépasser le maître en refondant cette culture roumaine sur des bases philosophiques qu'il va puiser lui aussi dans l'analyse kantienne de la conscience. Le philosophe de Königsberg est cependant vite débordé dans ses conclusions par une réflexion qui vise ni plus ni moins à réduire 
le dualisme de l'esprit et de la nature pour concevoir une métaphysique moniste où la réalité ultime est l'énergie, elle-même régie par un finalisme permettant de comprendre l'évolution des espèces et des civilisations humaines. Sont mises à contribution aussi bien les dernières avancées de la science, majoritairement allemandes - l'énergétisme de W. Ostwald, la psychophysique de G. T. Fechner et H. Helmholtz, la psychologie expérimentale de W. Wundt, l'embryologie de E. Haeckel, la sociologie de F. Tönnies et A. Vierkandt, entre autres références -, que les philosophies post-kantiennes de Fichte, de Schopenhauer et, dans une moindre mesure, celle de Nietzsche - dont Rădulescu-Motru est le premier introducteur en roumain ${ }^{17}$.

Ion Petrovici, qui fait dès 1925 une synthèse de l'influence kantienne en Roumanie, qualifie de « saine » et «bienfaisante » la substitution du rationalisme de Kant à l'empirisme de Condillac « pour la situation culturelle [de la Roumanie] lorsqu'elle était dans sa phase de tâtonnements intellectuels $»^{18}$. Il estime que la dimension critique du scepticisme des empiristes, si nécessaire pour combattre un dogmatisme régnant, est au contraire dangereuse en l'absence d'une culture philosophique ferme, alors que le caractère apodictique du rationalisme est plus efficace pour éveiller et soutenir les premières initiatives philosophiques. Le rationalisme critique de Kant combine ces qualités. Rien de plus stimulant en outre pour la formation philosophique de débutants, dans un contexte où domine la polémique superficielle, que la rigueur du raisonnement kantien, dit Petrovici. Rădulescu-Motru souscrit à cette lecture, en y ajoutant un point de vue qui éclaire son propre rapport à la philosophie kantienne. En plus de la solidité du point de départ, elle garantit aussi l'originalité du système : " À partir du XIXe siècle, on pourrait même soutenir que la production philosophique de chaque peuple européen est en rapport avec la compréhension qu'il a de la philosophie [de Kant]. Cette production est d'autant plus originale que la compréhension de Kant est plus profonde ${ }^{19}$ ». Là est l'explication du lien entre la fécondité métaphysique et la vivacité de la culture en Allemagne :

17. - Rădulescu-Motru publie en 1897 un petit ouvrage de présentation, $F$. W. Nietzsche. Viaţa şi filosofia sa [F. W. Nietzsche. Sa vie et sa pensée], avec de larges citations, en précisant dans la préface qu'il en désapprouve de nombreuses thèses, mais que celles-ci seront moins dangereuses si elles sont directement offertes au public que propagées par des zélateurs peu contrôlables.

18. - Ion Petrovici, « Kant şi cugetarea românească » [« Kant et la pensée roumaine »], dans Id., Din cronica filosofiei româneşti, Iaşi, Institutul European, 2005, p. 31.

19. - C. Rădulescu-Motru, « Filozofia lui Immanuel Kant » [« La philosophie d'Emmanuel Kant »], Viaţa Românească, 1924, 5, p. 211. 
Il y a une cinquantaine d'années, il était encore à la mode de ridiculiser la métaphysique. Il était tout particulièrement à la mode de ridiculiser la métaphysique allemande qui se fondait sur l'apriorisme de Kant. Les esprits superficiels voyaient dans ces préoccupations métaphysiques des Allemands la preuve la plus sûre que ceux-ci étaient inaptes à la vie pratique et que l'avenir allait les mener à la conquête du monde des rêves... Mais ces dernières années ont montré que le monde des rêves et la vie pratique ne sont justement pas si loin l'un de l'autre et qu'entre l'originalité des Allemands dans le domaine de la métaphysique et leur puissance sur le terrain de la vie pratique il n'y a en aucune façon une simple coïncidence ${ }^{20}$.

Fécondité de la thèse kantienne... Au point cependant d'inspirer des métaphysiques potentiellement dangereuses pour l'avenir de la pensée rationnelle si elles sont mises au service d'idées nationales. RădulescuMotru, revenant en 1943 sur le sens de son œuvre dont les aspects sinueux ont été soulignés, évoque ses propres hésitations et la ligne de crête, périlleuse, suivie par la pensée roumaine :

Je confesse que, avant de parvenir à ces conclusions, j'ai eu une tentation, une grande tentation. J'ai pensé un moment remplacer l'apriorisme de l'école kantienne par la structure ethnique, ou celle de la mentalité raciale, et à mettre ainsi à la place de la corrélation entre esprit humain et cosmos la corrélation entre l'esprit de l'homme et sa structure mentale de membre d'un peuple, ou d'une race, comme le font certains philosophes aujourd'hui, étrangers et même roumains. Dans ce cas, il m'aurait fallu considérer les vérités et les lois morales comme ayant une universalité et une nécessité contenues dans les limites du tempérament naturel de l'âme roumaine, et pas plus étendues. Par conséquent, il aurait fallu parler de temps et d'espace roumains, d'une logique roumaine, etc. Je ne suis pas tombé dans cette tentation, bien que cela m'eût rapporté une grande popularité de la part du public. Et je ne le regrette pas. Quel que soit son amour pour son peuple, en philosophie, il faut tout de même garder en considération le fait que le peuple appartient à l'humanité21.

Parmi les penseurs visés, il y a en particulier Lucian Blaga avec sa théorie de « l'espace mioritique » 22 comme « matrice » de l'âme

20. - C. Rădulescu-Motru, Elemente de metafizică pe baza filosofiei kantiane [Éléments de métaphysique sur la base de la philosophie kantienne], dans Id., Personalismul energetic şi alte scrieri [Le personnalisme énergétique et autres œuvres], Bucarest, Editura Eminescu, 1984, p. 401. p. 83.

21. - C. Rădulescu-Motru, Mărturisiri [Confessions], Bucureşti, Minerva, 1990,

22. - Titre du 2e tome de la Trilogie de la culture, publié par Blaga en 1935. L'adjectif renvoie à la ballade populaire « Mioriţa », évoquant l'assassinat d'un berger 
roumaine, qui utilise explicitement l'expression « apriorisme roumain » et extrapole, pour l'inconscient, l'idée de structures mentales préexistantes. Rădulescu-Motru a polémiqué avec lui, s'opposant nettement à sa démarche faisant du mystère, de la poésie et du patrimoine populaire la source privilégiée de l'inspiration philosophique, par opposition à la « philosophie scientifique » qu'il défendait lui-même. Leur commune référence à Kant sépare les deux auteurs tout en constituant un langage commun de la philosophie roumaine de l'entre-deux-guerres, et le « champ de bataille » de sa métaphysique, pour reprendre une célèbre expression kantienne. Il est étrange de voir comment en Roumanie la référence à Kant et à ses successeurs métaphysiciens se fait par-dessus la mise à l'écart des prétentions métaphysiques opérée par Kant lui-même, comme par Maiorescu.

Le débat sur la spécificité et l'originalité de la pensée roumaine s'exacerbe dans l'entre-deux-guerres et la philosophie allemande s'y retrouve impliquée. Accusée de nuire à la naissance d'une pensée proprement roumaine par les adversaires de Junimea, convoquée comme son meilleur fondement par les héritiers de Maiorescu et sollicitée aussi bien par leurs adversaires, y compris sous des figures plus contemporaines comme celles de Spengler, elle a de fait pris le pas sur la pensée française dans les débats roumains. Sans doute répondait-elle mieux aux aspirations du lieu et du moment, en particulier au besoin de métaphysique et d'une conception forte, c'est-à-dire identitaire, de la culture, bref, au besoin d'ancrage spirituel, qui caractérise l'élite roumaine et ses philosophes jusqu'à C. Noica inclus. Mais c'est aussi la pensée allemande qui a offert en Roumanie le cadre du dialogue fécond entre la philosophie et la science, inscrivant la pensée roumaine dans une incontestable modernité européenne.

moldave qui accepte son sort et, par la mort, de se fondre dans le paysage naturel des plateaux carpatiques qui a modelé son environnement et son être. 
